\title{
Aldosterone rapidly activates p-PKC delta and GPR30 but suppresses p-PKC epsilon protein levels in rat kidney
}

\author{
Somchit Eiam-Ong ${ }^{1}$, Mookda Chaipipat ${ }^{2}$, Krissanapong Manotham ${ }^{3}$, Somchai Eiam-Ong ${ }^{4}$ \\ ${ }^{1}$ Department of Physiology, Faculty of Medicine, Chulalongkorn University, Bangkok, Thailand; ${ }^{2}$ Department of Pathol- \\ ogy, Faculty of Medicine, Chulalongkorn University, Bangkok, Thailand; ${ }^{3}$ Department of Medicine, Lerdsin General \\ Hospital, Bangkok, Thailand; ${ }^{4}$ Department of Medicine (Division of Nephrology), Faculty of Medicine, Chulalongkorn \\ University, Thailand \\ E-mail:eiamong@yahoo.com
}

Objectives. Aldosterone rapidly enhances protein kinase $\mathrm{C}(\mathrm{PKC})$ alpha and betal proteins in the rat kidney. The G protein-coupled receptor 30 (GPR30)-mediated PKC pathway is involved in the inhibition of the potassium channel in HEK-239 cells. GPR30 mediates rapid actions of aldosterone in vitro. There are no reports available regarding the aldosterone action on other PKC isoforms and GPR30 proteins in vivo. The aim of the present study was to examine rapid actions of aldosterone on protein levels of phosphorylated PKC (p-PKC) delta, p-PKC epsilon, and GPR30 simultaneously in the rat kidney.

Methods. Male Wistar rats were intraperitoneally injected with normal saline solution or aldosterone $(150 \mu \mathrm{g} / \mathrm{kg}$ body weight). After 30 minutes, abundance and immunoreactivity of p-PKC delta, p-PKC epsilon, and GPR30 were determined by Western blot analysis and immunohistochemistry, respectively.

Results. Aldosterone administration significantly increased the renal protein abundance of $\mathrm{p}$ PKC delta by $80 \%(\mathrm{p}<0.01)$ and decreased $\mathrm{p}$-PKC epsilon protein by $50 \%(\mathrm{p}<0.05)$. Aldosterone injection enhanced protein immunoreactivity of p-PKC delta but suppressed p-PKC epsilon protein intensity in both kidney cortex and medulla. Protein abundance of GPR30 was elevated by aldosterone treatment $(p<0.05)$, whereas the immunoreactivity was obviously changed in the kidney cortex and inner medulla. Aldosterone translocated p-PKC delta and GPR30 proteins to the brush border membrane of proximal convoluted tubules.

Conclusions. This is the first in vivo study simultaneously demonstrating that aldosterone administration rapidly elevates protein abundance of p-PKC delta and GPR30, while p-PKC epsilon protein is suppressed in rat kidney. The stimulation of p-PKC delta protein levels by aldosterone may be involved in the activation of GPR30.

Key words: aldosterone, rapid action, p-PKC delta, p-PKC epsilon, GPR30, protein abundance, immunohistochemistry, rat kidney

Aldosterone has been shown to have rapid nongenomic effects in a variety of tissues (Grossmann and Gekle 2009; Thomas and Harvey 2011; Dooley et al. 2012). This process acts rapidly ( $\leq 30 \mathrm{~min})$ and is insensitive to transcription or translation inhibitors
(Grossmann and Gekle 2009; Thomas and Harvey 2011; Dooley et al. 2012). Protein kinase C (PKC) is one of the crucial signal transductions activated by rapid actions of aldosterone (Thomas et al. 2007). It has been shown that aldosterone rapidly elevates PKC

Corresponding author: Associate Professor Somchit Eiam-Ong, PhD., Department of Physiology, Faculty of Medicine, Chulalongkorn University, Bangkok, Thailand 10330; phone: (662) 256-4267; fax: (662) 256-4267; e-mail: eiamong@yahoo.com. 
alpha and PKC betal in rat kidney (Eiam-Ong et al. 2014; Eiam-Ong et al. 2017). However, no data are available to demonstrate the rapid effects of aldosterone on other PKC isoforms such as PKC delta or PKC epsilon. A previous in vitro study in cardiac myocytes has shown that aldosterone administration increases $\mathrm{Na}^{+} / \mathrm{K}^{+} / 2 \mathrm{Cl}^{-}$cotransporter activity within $15 \mathrm{~min}$ mediated by PKC epsilon (Mihailidou et al. 2004). In addition, G protein-coupled receptor 30 (GPR30) mediates rapid actions of aldosterone in vitro (Gros et al. 2011a; Brailoiu et al. 2013). The GPR30-mediated PKC pathway is involved in the inhibition of potassium channel in HEK-239 cells (Dong et al. 2013). There are no in vivo studies available regarding the rapid actions of aldosterone on other PKC isoforms (delta and epsilon) or GPR30 proteins.

The present study is aimed to investigate rapid alterations induced by aldosterone on the protein levels of phosphorylated PKC (p-PKC) delta, p-PKC epsilon, and GPR30 simultaneously in the rat kidney. The protein abundance of p-PKC (delta and epsilon), and GPR30 were measured by Western blotting 30 min after aldosterone injection. The localization and distribution of these proteins were examined by immunohistochemistry.

\section{Materials and methods}

Animals. Male Wistar rats 6-8 weeks old, weighing 200-240 g, and pathogenically free, were obtained from the National Center of Scientific Use of Animals, Mahidol University, Nakornpathom, Thailand. The rats were housed in a room with controlled temperature $\left(23 \pm 1^{\circ} \mathrm{C}\right), 12$-hour light/dark cycle. Animals were fed with a regular rat chow (dry pellets) and tap water ad libitum (Sinphitukkul et al. 2011; Eiam-Ong et al. 2013; Eiam-Ong et al. 2014; Eiam-Ong et al. 2017). The rats were acclimatized for 3 days before starting the experiment. All the animal protocols were approved by the Ethics Committee of Research, Chulalongkorn University (Permit number IRB 03/56). The serum creatinine of each rat should be $<1 \mathrm{mg} / \mathrm{dl}$ (Sinphitukkul et al. 2011; Eiam-Ong et al. 2013; Eiam-Ong et al. 2014; Eiam-Ong et al. 2017).

Experimental design. The rats were divided into two groups ( $\mathrm{n}=6 /$ group): vehicle (normal saline solution; NSS: $0.5 \mathrm{ml} / \mathrm{kg}$ body weight (b.w.) by intraperitoneal injection (i.p.); and Aldo (aldosterone $150 \mu \mathrm{g} / \mathrm{kg}$ b.w., diluted in NSS, i.p.; Sigma, St. Louis, MO, USA) (Sinphitukkul et al. 2011; Eiam-Ong et al. 2013; Eiam-Ong et al. 2014; Eiam-Ong et al. 2017). We used this dose as previously performed in studies on rapid actions of aldosterone on the protein levels of PKCa, $\alpha_{1}-\mathrm{Na}^{+}, \mathrm{K}^{+}$-ATPase, PKC $\beta$ (I and II) and NHE (1 and 3) (Eiam-Ong et al. 2014; Eiam-Ong et al. 2017). Therefore, in the present investigation, we further examine the effect of this dose on $\mathrm{p}$-PKC (delta and epsilon) and GPR30 protein levels.

On the day of the experiment, $30 \mathrm{~min}$ after NSS or aldosterone injection, the rats were anesthetized with thiopental (100 mg/kg b.w., i.p.) (Eiam-Ong et al. 2013; Eiam-Ong et al. 2014; Eiam-Ong et al. 2017). Plasma samples obtained from the abdominal aorta were stored at $-80^{\circ} \mathrm{C}$ until use for the measurement of aldosterone levels by a radioimmunoassay kit (Aldo-Riact; CIS Bio International, Gif-sur-Yvette, France). Blood and urine chemistry were measured by an indirect method (Model CX3; Beckman, Krefeld, Germany). The kidneys were removed, and half of each kidney was fixed in liquid nitrogen, and then stored at $-80^{\circ} \mathrm{C}$ until use for the measurement of p-PKC (delta and epsilon) and GPR30 protein abundance by Western blot analysis. The other half of the renal tissue was fixed in $10 \%$ paraformaldehyde, subjected to tissue processing by an automate tissue processor (Shandon Citadel 2000, Thermo Scientific, Rockford, IL, USA), and embedded into paraffin wax for localization and distribution of these proteins by immunohistochemistry (Eiam-Ong et al. 2013; Eiam-Ong et al. 2014; Eiam-Ong et al. 2017).

Western blotting. Electrophoresis and immunoblotting were performed as previously described (Eiam-Ong et al. 2013; Eiam-Ong et al. 2014; EiamOng et al. 2017). Briefly, renal tissue samples were homogenized on ice and centrifuged at $12000 \times \mathrm{g}$ (Biofuge PrimoR, Heracus, Germany) for $20 \mathrm{~min}$ at $4{ }^{\circ} \mathrm{C}$ to remove crude debris. The supernatant parts were collected for homogenate samples. To harvest the plasma membrane, the supernatant was further centrifuged at $17000 \times \mathrm{g}$ for $20 \mathrm{~min}$ at $4{ }^{\circ} \mathrm{C}$. The pellet was re-suspended in buffer (Fernandez-Llama et al. 2000; Eiam-Ong et al. 2014; Eiam-Ong et al. 2017). The total protein concentrations of both homogenate samples and plasma membranes were measured as previously described (Eiam-Ong et al. 2014; Eiam-Ong et al. 2017). The measurement of protein abundance was performed as previously described (Eiam-Ong et al. 2014; Eiam-Ong et al. 2017). Homogenate $(120 \mu \mathrm{g}$ protein) or plasma membrane (100 $\mu$ g protein) samples were mixed sample buffer and separated on $8 \%$ sodium dodecyl sulfate polyacrylamide gel electrophoresis (SDS-PAGE). The proteins were transferred to nitrocellulose membrane (Bio-Rad, Hercules, CA, USA), and blocked in buffer containing $5 \%$ nonfat dry milk in $0.5 \%$ Tween 20 . The membranes were incubated with a primary poly- 
clonal antibody to p-PKC delta (Ser643/676; 1:1000; Cell Signaling Technology, Danvers, MA, USA) (Parker et al. 2016), p-PKC epsilon (Ser 729: sc-12355; 1:200; Santa Cruz Biotechnology, Dallas, CA, USA) (Fan et al. 2009), GPR30 (K-19-R: sc-48524-R; 1:500; Santa Cruz Biotechnology) (Batenburg et al. 2012), or $\beta$-actin (Santa Cruz Biotechnology), followed by the respective horseradish peroxidase-linked secondary antibody (Bio-Rad). Immunoreactive proteins were detected by chemiluminescence (SuperSignal West Pico kit; Pierce), and band intensity was measured densitometrically with molecular imager ChemiDoc XRS system (Bio-Rad). The relative protein levels of p-PKC (delta and epsilon) and GPR30 in each sample were present as a percentage of the control normalized to its $\beta$-actin content.

Immunohistochemitry. Detection of protein localization was performed as previously described (Eiam-Ong et al. 2013; Eiam-Ong et al. 2014; EiamOng et al. 2017). Paraffin-embedded kidney was cut into $4 \mu \mathrm{m}$ thick sections. The sections were deparaffinized and endogenous peroxidase was blocked by treatment with $3 \% \mathrm{H}_{2} \mathrm{O}_{2}$. The sections were then incubated with the primary antibody to p-PKC delta (1:1000; Cell Signaling), p-PKC epsilon (1:500; Santa Cruz Biotechnology), or GPR30 (1:500; Santa Cruz Biotechnology), at $4^{\circ} \mathrm{C}$ overnight, followed by the respective horseradish peroxidase-linked secondary antibody (Bio-Rad), and then reacted with

Table 1

Blood and urine chemistry in experimental groups.

\begin{tabular}{lcc}
\hline Parameter & Vehicle & Aldo \\
\hline $\begin{array}{l}\text { Plasma aldosterone } \\
\text { (pmol/l) }\end{array}$ & $1522.11 \pm 12.45$ & $6408.13 \pm 98.18^{*}$ \\
$\begin{array}{l}\text { Plasma sodium } \\
\text { (mmol/l) }\end{array}$ & $139.33 \pm 1.36$ & $141.22 \pm 5.82$ \\
$\begin{array}{l}\text { Plasma potassium } \\
\text { (mmol/l) }\end{array}$ & $3.73 \pm 0.12$ & $3.66 \pm 0.28$ \\
\hline $\begin{array}{l}\text { Plasma chloride } \\
\text { (mmol/l) }\end{array}$ & $101.14 \pm 2.14$ & $102.44 \pm 2.67$ \\
$\begin{array}{l}\text { Plasma bicarbonate } \\
\text { (mmol/l) }\end{array}$ & $24.52 \pm 1.54$ & $25.02 \pm 2.08$ \\
$\begin{array}{l}\text { Plasma creatinine } \\
\text { (mg/dl) }\end{array}$ & $0.24 \pm 0.02$ & $0.24 \pm 0.02$ \\
\hline $\begin{array}{l}\text { Blood urea nitrogen } \\
\text { (mg/dl) }\end{array}$ & $20.12 \pm 1.38$ & $21.12 \pm 3.18$ \\
$\begin{array}{l}\text { Ratio of plasma } \\
\text { sodium to potassium }\end{array}$ & $41.48 \pm 3.94$ & $40.82 \pm 2.88$ \\
\hline $\begin{array}{l}\text { Ratio of urinary } \\
\text { sodium to potassium }\end{array}$ & $0.32 \pm 0.02$ & $0.33 \pm 0.02$ \\
\hline
\end{tabular}

Data are expressed as means $\pm S D, n=6 /$ group. ${ }^{\star} \mathrm{p}<0.001$ vs. vehicle.
3, 3'-diaminobenzidine (DAB) solution (Sigma). As a negative control, the primary antibody was omitted, resulting in negative staining. Three blinded investigators independently examined and scored the staining intensity on a semi-quantitative five-tiered grading scale from 0 to $4(0=$ negative; $1=$ trace; 2 = weak; $3=$ moderate; $4=$ strong) as previously described (Eiam-Ong et al. 2013; Eiam-Ong et al. 2017; Fujigaki et al. 2007).

Statistical analysis. The results of renal p-PKC (delta and epsilon) and GPR30 protein abundance were expressed as the mean \pm SD. Student's t-test for independent groups was used to analyze statistical differences. A p-value of $<0.05$ was considered statistically significant. Statistical tests were analyzed using SPSS program version 22.0 (SPSS Inc., Chicago, IL, USA). The median staining intensity (score) of renal p-PKC (delta and epsilon) and GPR30 protein levels was presented as previously described (EiamOng et al. 2013; Eiam-Ong et al. 2014; Eiam-Ong et al. 2017).

\section{Results}

Blood and urine biochemical results. As shown in Table 1, plasma aldosterone levels significantly increased in the Aldo group compared with the vehicle group $(p<0.001, d f=10)$. There were no significant changes in plasma sodium, potassium, chloride, bicarbonate, creatinine, or blood urea nitrogen between vehicle and Aldo groups. Aldosterone administration did not significantly alter the ratio of plasma sodium to potassium or the ratio of urinary sodium to potassium compared with vehicle group.

Protein abundance of renal p-PKC (delta and epsilon) and GPR30. By Western blot analysis (Figure 1), the protein levels of p-PKC delta $(78 \mathrm{kDa})$, p-PKC epsilon $(72 \mathrm{kDa})$, and GPR30 (38 kDa) were assessed. Aldosterone administration enhanced protein abundance of renal $\mathrm{p}$-PKC delta from $100 \%$ in the vehicle group to $180 \pm 9 \%(p<0.01)$, but p-PKC epsilon protein declined to $52 \pm 4 \%, \mathrm{p}<0.05$ $(\mathrm{n}=6 /$ group, $\mathrm{df}=10)$. GPR30 protein abundance was elevated by aldosterone treatment from $100 \%$ in the vehicle group to $135 \pm 11 \%, \mathrm{p}<0.05$ ( $\mathrm{n}=6 /$ group, $\mathrm{df}=10$ ).

Protein localization of renal p-PKC delta. The protein localization of p-PKC delta in the cortex of the vehicle group is demonstrated in Figure $2 \mathrm{~B}$ and Table 2. The immunoreactivity was trace in the glomerulus (GL) and the proximal convoluted tubule (PCT). The staining revealed strong level in the cortical collecting duct (CCD) and moderate level in the peritubular capillary (Pcap). No staining was 
Table 2

Median staining intensity (score) of renal p-PKC delta, p-PKC epsilon and GPR30 protein localization.

\begin{tabular}{|c|c|c|c|c|c|c|}
\hline \multirow{3}{*}{ Region } & \multicolumn{6}{|c|}{ Median staining intensity (score) } \\
\hline & \multicolumn{2}{|c|}{ p-PKC delta } & \multicolumn{2}{|c|}{ p-PKC epsilon } & \multicolumn{2}{|c|}{ GPR30 } \\
\hline & Vehicle & Aldo & Vehicle & Aldo & Vehicle & Aldo \\
\hline
\end{tabular}

Cortex

$\begin{array}{lllllll}\text { GL } & 1 & 1 & 1 & 1 & 1 & 1 \\ \text { PCT } & 1 & 3 & 1 & 0 & 2 & 3 \\ \text { DCT } & 0 & 0 & 0 & 0 & 2 & 2 \\ \text { CCD } & 4 & 4 & 4 & 1 & 3 & 2 \\ \text { Pcap } & 3 & 3 & 1 & 1 & 1 & 1\end{array}$

Outer

Medulla

\begin{tabular}{lllllll} 
TALH & 1 & 2 & 1 & 0 & 0 & 1 \\
MCD & 2 & 4 & 1 & 0 & 1 & 1 \\
VR & 1 & 2 & 1 & 1 & 0 & 1 \\
tLH & 1 & 1 & 1 & 1 & 0 & 1 \\
$\begin{array}{l}\text { Inner } \\
\text { Medulla }\end{array}$ & & & & & \\
MCD & 2 & 2 & 2 & 1 & 1 & 1 \\
VR & 1 & 2 & 2 & 2 & 1 & 3 \\
tLH & 1 & 2 & 2 & 1 & 1 & 3 \\
\hline
\end{tabular}

Staining intensity: $0=$ negative, no reactivity; $1=$ trace, faint or pale brown staining with less membrane reactivity; 2 = weak, light brown staining with incomplete membrane reactivity, $3=$ moderate, shaded of brown staining of intermediate darkness with usually almost complete membrane reactivity; $4=$ strong, dark brown to black staining with usually complete membrane pattern, producing a thick outline of the cell (Eiam-Ong et al. 2017).

Abbreviations: GL - glomerulus; PCT - proximal convoluted tubule; DCT - distal convoluted tubule; CCD - cortical collecting duct; Pcap - peritubular capillary; TALH - thick ascending limb of the loop of Henle; MCD - medullary collecting duct; VR - vasa recta; tLH - thin limb of the loop of Henle ( $n=5$ / group).

noted in the distal convoluted tubule (DCT). Aldosterone treatment increased the intensity score only in the PCT from 1 to 3 with the obvious staining at the brush border membrane (Figure 2C). Aldosterone injection did not change the intensity score in the CCD but translocated the immunoreactivity from the cytosolic compartment to the plasma membrane area.

In the outer medulla (OM), aldosterone administration elevated the intensity score from 2 to 4 in the medullary $\mathrm{CD}(\mathrm{MCD})$, whereas staining in the thick ascending limb of the loop of Henle (TALH),

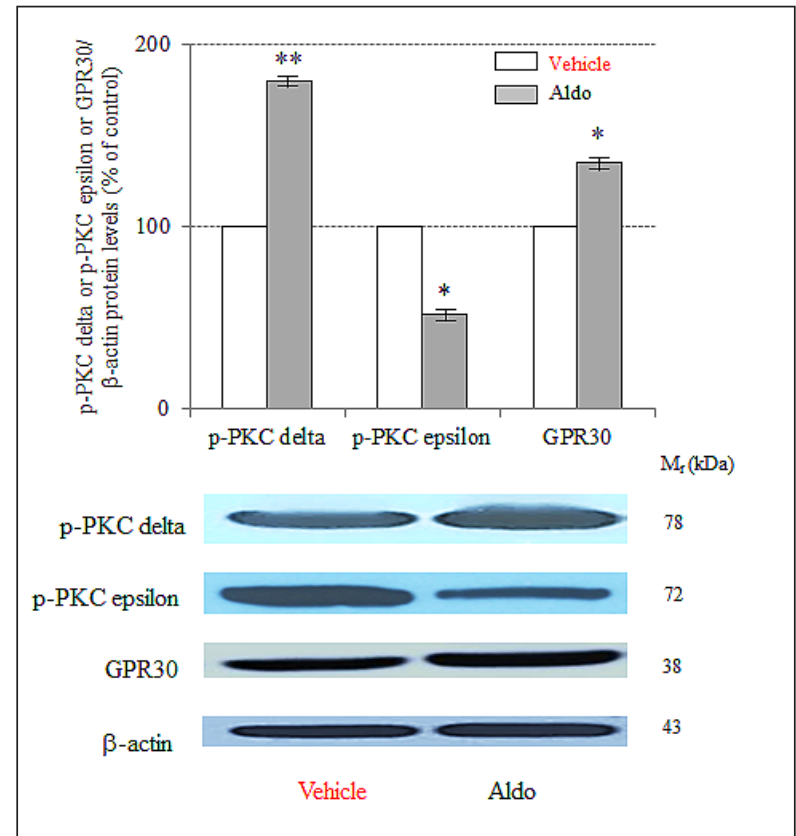

Figure 1. Western blot analysis of renal p-PKC delta, p-PKC epsilon, and GPR30 protein abundance in vehicle and Aldo groups. Histogram bars show the densitometric analyses ratios of p-PKC delta, p-PKC epsilon or GPR30 to $\beta$-actin intensity, and the representative immunoblot photographs are present. Data are means $+S D$ of 6 independent experiments. ${ }^{*} p<0.05$, ${ }^{*} \mathrm{p}<0.01$ vs. vehicle.

and vasa recta (VR) was increased to weak levels (Figure 2F and Table 2). In the inner medulla (IM), aldosterone treatment enhanced immunoreactivity to weak levels in the VR and tLH, but the intensity score in the MCD did not change. (Figure 2I). Aldosterone injection obviously induced immunostaining at plasma membranes of the MCD (Figures 2F, 2I).

Protein localization of renal p-PKC epsilon. The protein localization of $\mathrm{p}-\mathrm{PKC}$ epsilon in the cortex in the vehicle group is shown in Figure 3B and Table 2. The immunoreactivity was trace in the GL, Pcap, and PCT, but no staining was noted in the DCT. Aldosterone administration decreased the staining score from 4 to 1 in the CCD and from 1 to 0 in the PCT (Figure 3C). The immunoreactivity in the GL and the Pcap did not change. In the OM, aldosterone treatment suppressed the intensity score from 1 to 0 in the TALH and MCD. The intensity score in the VR and tLH remained trace levels (Figure $3 \mathrm{~F}$ and Table 2). In the IM, immunoreactivity was lowered to trace levels in the MCD and tLH by aldosterone injection (Figures 3I).

Protein localization of renal GPR30. As shown in Figure $4 \mathrm{~B}$ and Table 2, in the cortex in the vehicle 


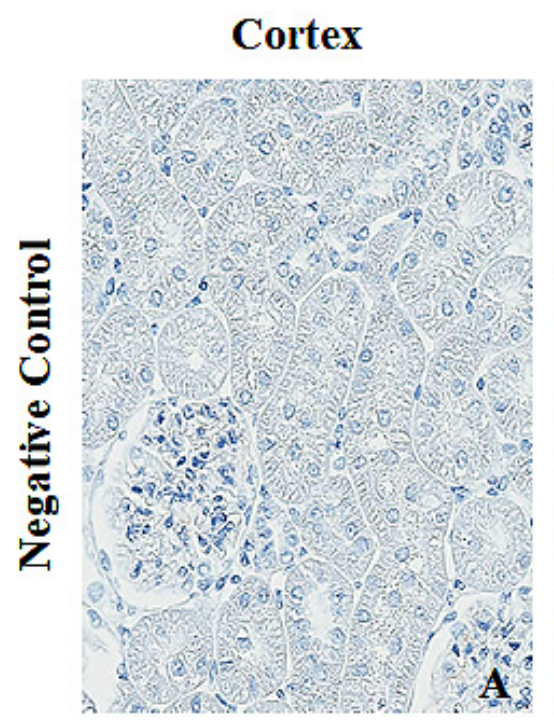

Outer medulla
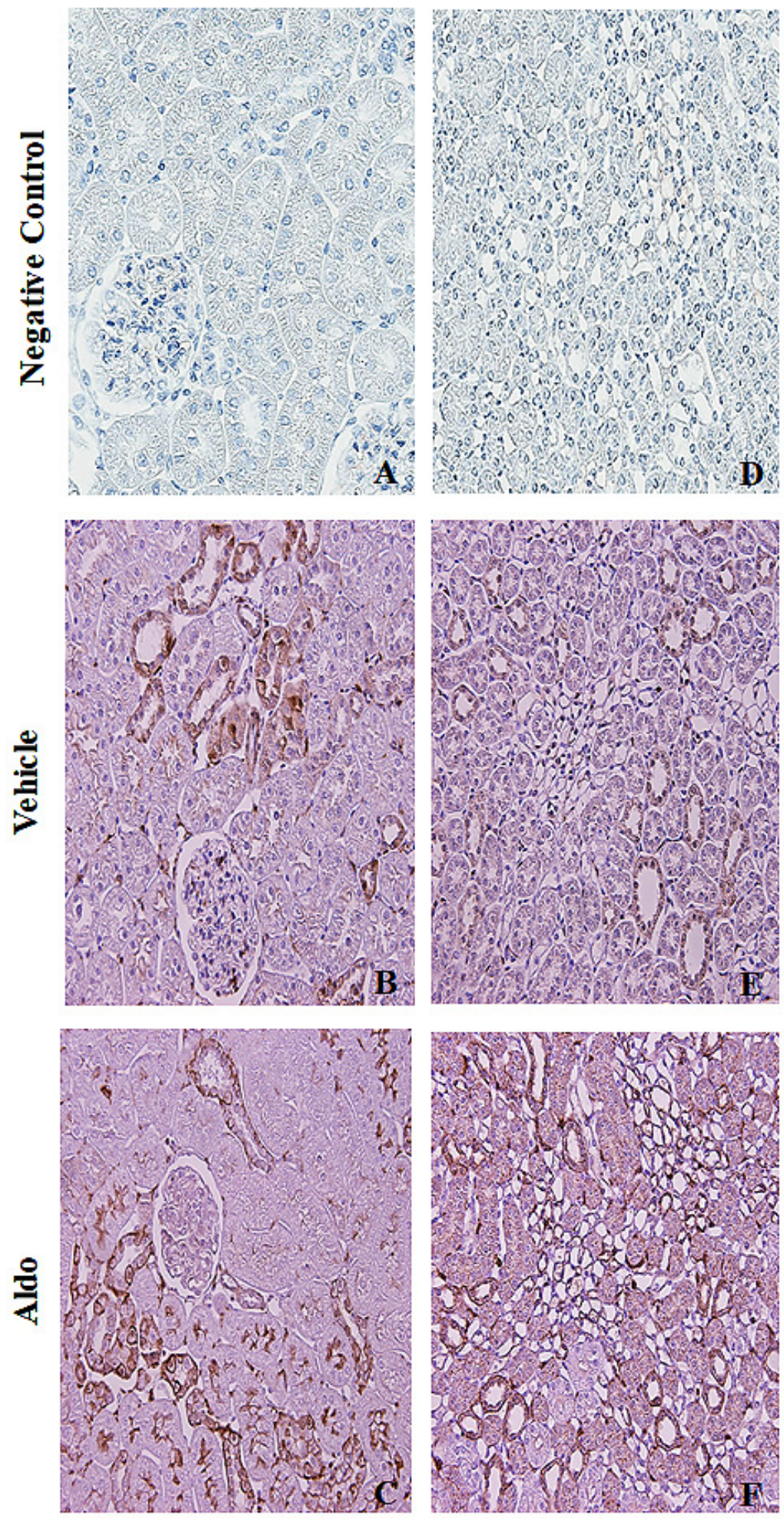
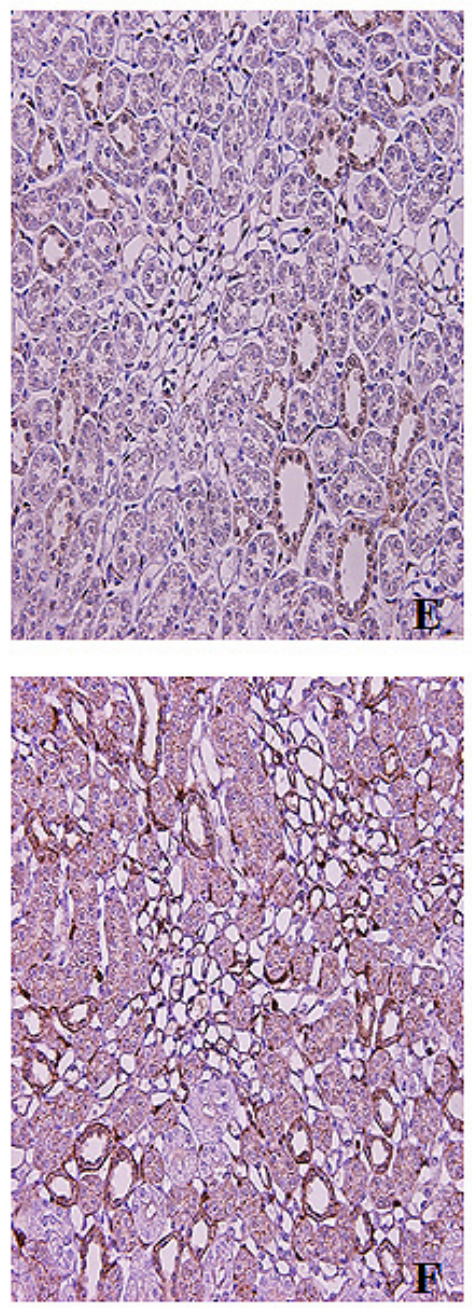

Inner medulla
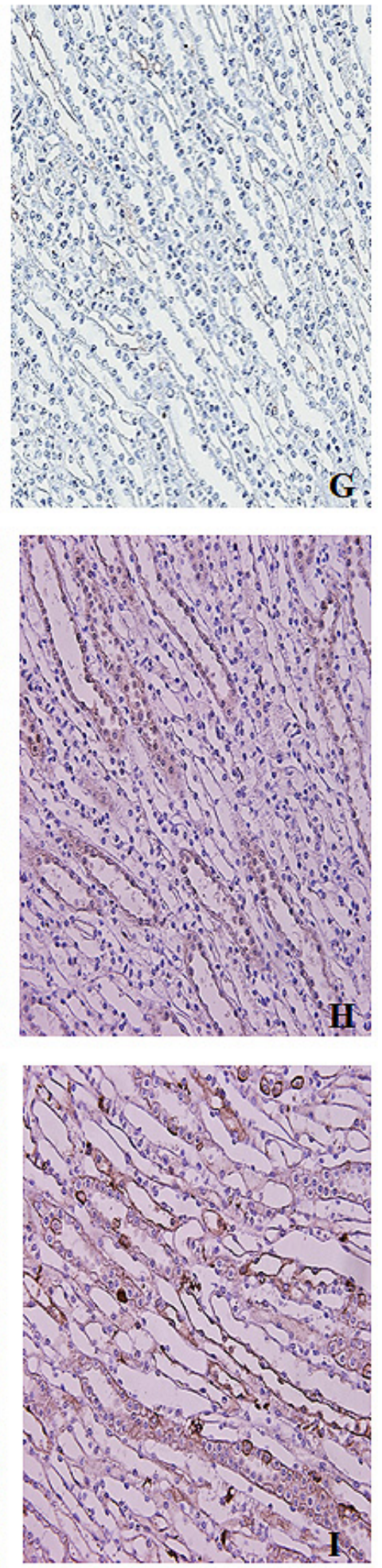

Figure 2. Representative immunohistochemical staining micrographs of renal p-PKC delta protein localization in the cortex (A-C), the outer medulla $(\mathbf{D}-\mathbf{F})$, and the inner medulla $(\mathbf{G}-\mathbf{I})$ from vehicle $(\mathbf{B}, \mathbf{E}, \mathbf{H})$ and Aldo $(\mathbf{C}, \mathbf{F}, \mathbf{I})$ (n=5/group). Negative controls (A, D, G). Original magnification, $\times 400(A-C)$ and $\times 200(D-I)$. 


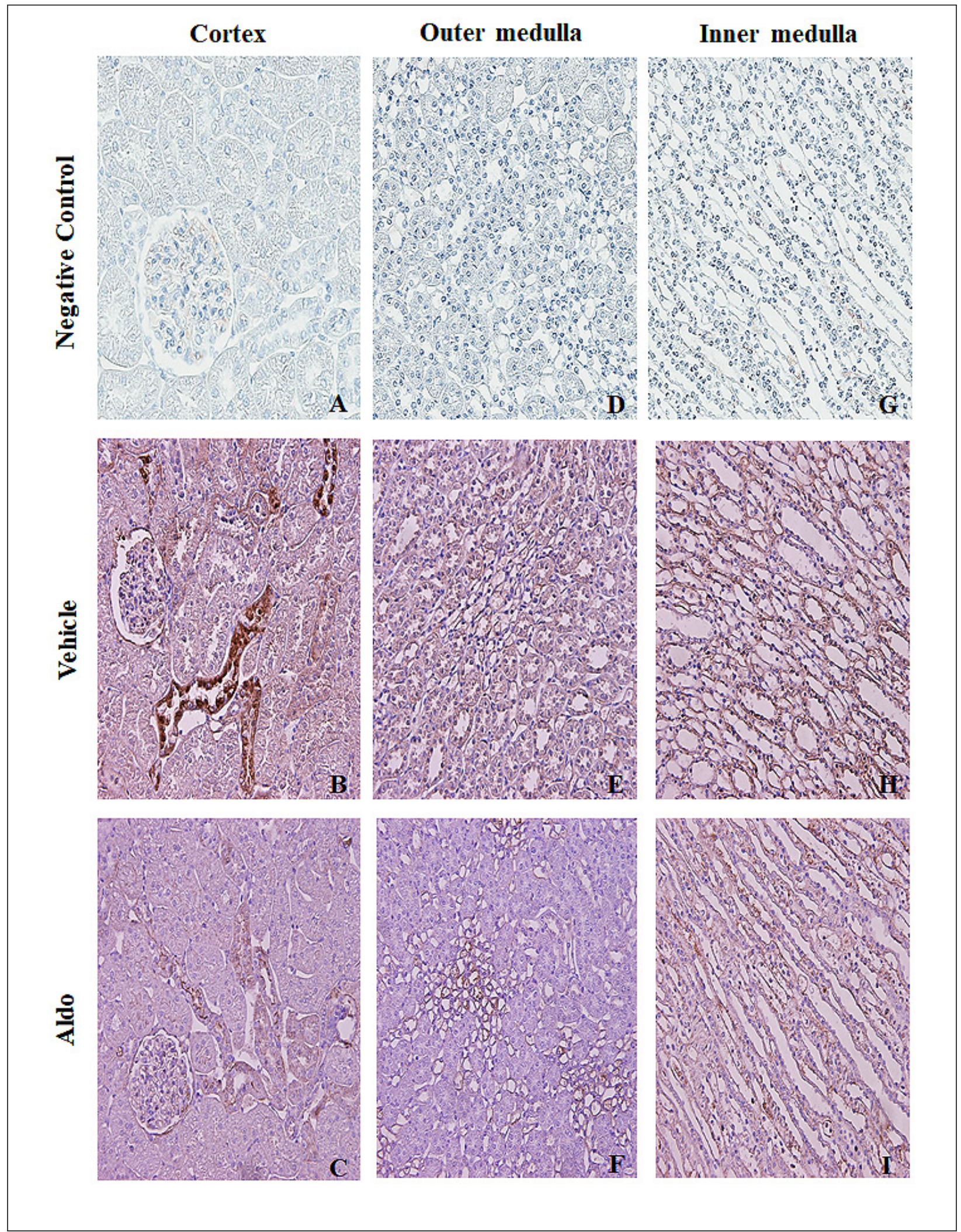

Figure 3. Representative immunohistochemical staining micrographs of renal p-PKC epsilon protein localization in the cortex $(\mathbf{A}-\mathbf{C})$, the outer medulla (D-F), and the inner medulla (G-I) from vehicle (B, E, H) and Aldo (C, F, I) (n=5/group). Negative controls (A, D, G). Original magnification, $\times 400($ A-C) and $\times 200($ D-I). 


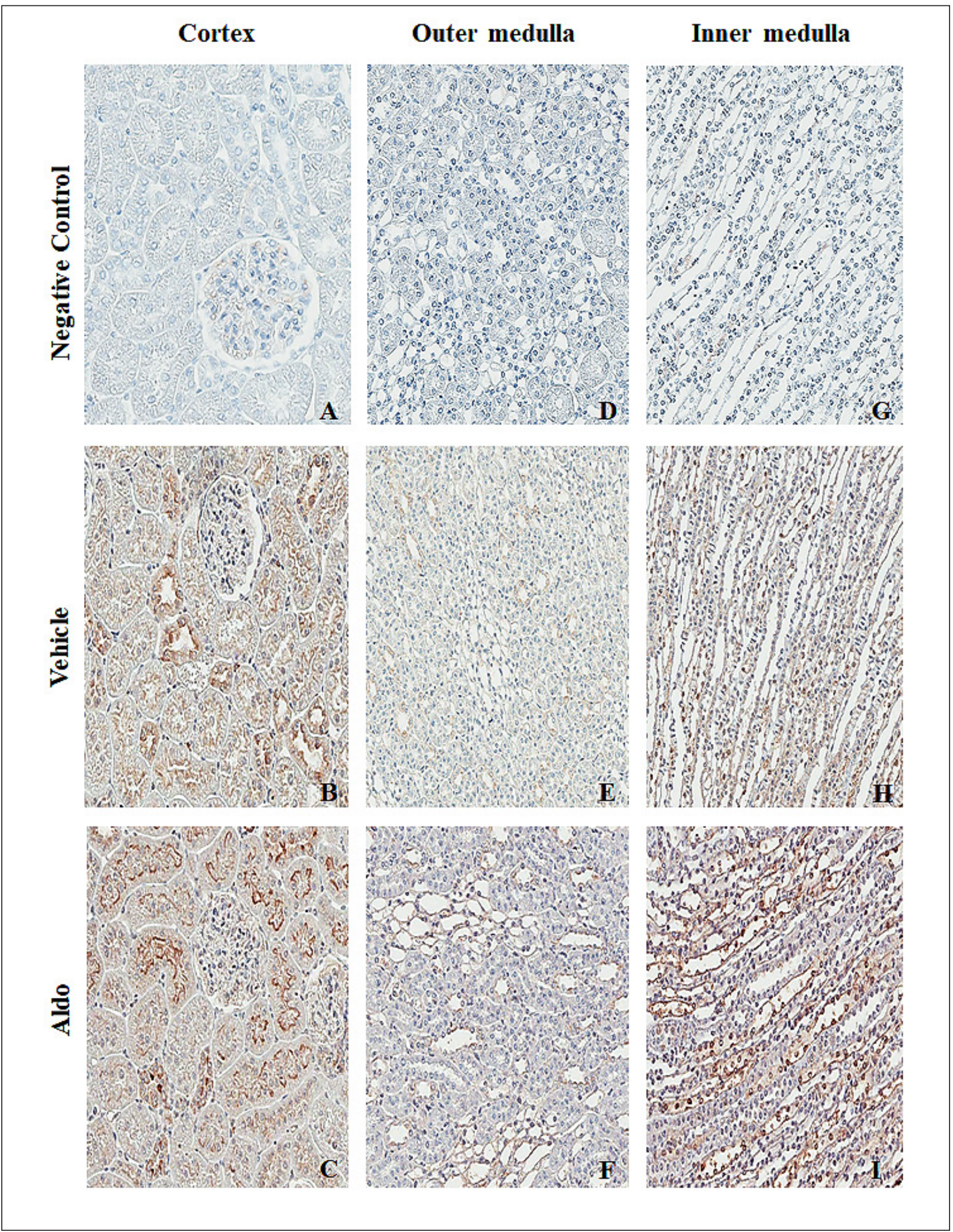

Figure 4. Representative immunohistochemical staining micrographs of renal GPR30 protein localization in the cortex (A-C), the outer medulla (D-F), and the inner medulla (G-I) from vehicle (B, E, H) and Aldo (C, F, I) (n=5/group). Negative controls (A, D, G). Original magnification, $\times 400(\mathbf{A}-\mathrm{C})$ and $\times 200(\mathrm{D}-\mathrm{I})$. 
group, the immunoreactivity of renal GPR30 protein showed trace diffuse staining in the GL and the Pcap. The weak diffuse staining was observed in the PCT and DCT, whereas the staining in the CCD was moderate (Figure 4B). Aldosterone administration increased the intensity score at the luminal side of the PCT from 2 to 3, but reduced the score from 3 to 2 in the CCD (Figure 4C). The immunoreactivity in the GL, Pcap, and DCT was unchanged by aldosterone treatment. In the OM, aldosterone injection increased the staining to trace levels (score=1) in the TALH, $\mathrm{VR}$, and tLH, but the staining was unchanged in the MCD (Figure 4F). In the IM, immunoreactivity was elevated to moderate levels in the VR and the tLH by aldosterone treatment while the intensity score in the MCD was unchanged (Figure 4I and Table 2).

\section{Discussion}

The present results provide the first in vivo data simultaneously showing renal p-PKC delta, $\mathrm{p}$-PKC epsilon, and GPR30 protein abundance as well as immunoreactivity 30 minutes following aldosterone administration. Aldosterone treatment significantly enhanced the renal protein abundance of $\mathrm{p}$-PKC delta by $80 \%$, whereas $\mathrm{p}-\mathrm{PKC}$ epsilon protein tended to reduce (Figure 1). Activation of PKC family is a notable consequence of rapid effects induced by aldosterone (Thomas et al. 2007). This may explain by aldosterone-induced transient increases in intracellular $\mathrm{Ca}^{2+}$ levels, which then activate $\mathrm{Ca}^{2+}$-dependent PKCs (Harvey and Higgins 2000; Le Moellic et al. 2004). We previously demonstrated in the rat kidney that aldosterone injection for 30 minutes increased protein abundance of PKCa and enhanced immunoreactivity staining of PKCa in the PCT with the translocation from basolateral to luminal membranes (Eiam-Ong et al. 2014). Recently, we have shown that aldosterone injection for $30 \mathrm{~min}$ also elevated protein abundance and immunostaining intensity of PKC $\beta I$ in the rat kidney (Eiam-Ong et al. 2017).

Protein kinase C (PKC) is a family of closely related serine/ threonine kinases and plays a crucial role in cellular signal transduction and cellular effector functions (Newton 1995; Schnaper 2000). PKC delta and PKC epsilon are isoforms in the new PKC (nPKC) family (Nishizuka 1988; Nishizuka 1992). There are no available data showing the rapid effect of aldosterone on these protein abundances. Our present data provide the first evidence in the rat kidney that aldosterone treatment rapidly activates $\mathrm{p}$-PKC delta protein abundance but suppresses p-PKC epsilon protein level. This result implies that by contributing its rapid effect aldosterone shows diverse effects on p-PKC delta and p-PKC epsilon. These two isozymes have different and sometimes opposite effects (Duquesnes et al. 2011). PKC delta promotes apoptosis while PKC epsilon stimulates cell growth and differentiation (Duquesnes et al. 2011). The precise mechanism, by which aldosterone administration may enhance PKC delta protein abundance has not been established. PKC delta protein levels have been demonstrated to be enhanced after incubation with reactive oxygen species (Lee et al. 2005). Interestingly, aldosterone rapidly induced oxidative stress production (Queisser et al. 2011; Zhu et al. 2011). We propose that the increased p-PKC delta protein abundance in the present study may be mediated via oxidative stress induced by aldosterone. PKC delta has been shown to regulate cotransporter activity during alpha-adrenergic stimulation (Liedtke and Cole 1997; Liedtke et al. 2001), $\mathrm{Na}^{+} / \mathrm{K}^{+} / 2 \mathrm{Cl}^{-}$activity (Liedtke and Cole 2002; Liedtke et al. 2002), and $\mathrm{Na}^{+}, \mathrm{K}^{+}$-ATPase exocytosis (Ridge et al. 2002).

For PKC epsilon, the present results show that aldosterone administration decreased p-PKC epsilon protein abundance in the rat kidney. The precise mechanism, by which aldosterone suppressed PKC epsilon protein abundance has not been clarified yet. It has been shown that in rabbit cardiomyocytes, aldosterone rapid nongenomically activates $\mathrm{Na}^{+} / \mathrm{K}^{+} / 2 \mathrm{Cl}^{-}$cotransporter activity mediated by PKC epsilon (Mihailidou et al. 2004). We speculate that it may be the tissue-specific effect of aldosterone on the suppression p-PKC epsilon the kidney. In addition, in alveolar epithelial type II cells, dopamine increased $\mathrm{Na}^{+}, \mathrm{K}^{+}$-ATPase activity through the exocytosis of the pumps from late endosomes into the basolateral membrane in a mechanism-dependent activation of PKC epsilon (Ridge et al. 2002). Moreover, PKC epsilon also contributes to regulation of the sarcolemmal $\mathrm{Na}^{+}, \mathrm{K}^{+}$-ATPase pump (Buhagiar et al. 2001).

For the immunolocalization of PKC delta and PKC epsilon, the baseline distribution of both isoforms is consistent with the previous studies (Kang et al. 1999; Redling et al. 2004). The present data show that aldosterone administration increases the immunoreactivity of $\mathrm{p}-\mathrm{PKC}$ delta protein in the PCT, $\mathrm{tLH}$, VR, and CD. By contrast, p-PKC epsilon immunoreactivity was suppressed in both kidney cortex and medulla areas. The present results indicate that in a rapid pathway aldosterone diversely regulates protein distribution of p-PKC delta and p-PKC epsilon along the nephron. These proteins can consequently modulate myriad renal tubular ion transport (Newton 1995; Schnaper 2014). 
For GPR30, the present study shows the first time that aldosterone administration for 30 minutes increases protein abundance by $35 \% \quad(\mathrm{p}<0.05)$ (Figure 1). GPR30 belongs to the seven-transmembrane receptor (7TMR) superfamily (Filardo et al. 2006). The first receptor characterized as an "orphan G protein-coupled receptor," is expressed on the cell surface and mediates its effects via several members of the G protein family of GTP-binding proteins (Carmeci et al. 1997). The precise mechanism, by which aldosterone administration enhances GPR30 protein abundance has not been established. Despite the fact that the receptors mediating faster effects of aldosterone remained unclear, recent evidence has indicated that GPR30 may mediate the nongenomic effects of aldosterone (Feldman and Gros 2011; Funder 2011; Gros et al. 2011a; Gros et al. 2011b; Gros et al. 2013). It has been reported that aldosterone increases cardiac vagal tone via GPR30 activation (Brailoiu et al. 2013).

For GPR30 localization, the immunostaining of GPR30 protein in the vehicle group revealed a similar baseline regional distribution as previously described (Cheng et al. 2011; Lindsey et al. 2011; Cheng et al. 2014). The present data show that aldosterone administration rapidly induces GPR30 protein immunoreactivity in both the kidney cortex and medulla regions with a profound translocation of GPR30 protein to the apical membrane of proximal tubules (Figure 4C). This result implies that rapid effects of aldosterone play an important role in the regulation of renal tubular function. For example, aldosterone sensitized connecting tubule glomerular feedback via the receptor GPR30 (Ren et al. 2014). Moreover, mechanisms of connecting tubule glomerular feedback enhancement by aldosterone mediated via PKC (Ren et al. 2016). The GPR30-mediated PKC pathway is involved in the inhibition of potassium channel in HEK-239 cells (Dong et al. 2013).

\section{Conclusion}

This is the first in vivo study simultaneously demonstrating that aldosterone administration rapidly elevates protein levels of p-PKC delta and GPR30, but p-PKC epsilon was suppressed in the rat kidney. The stimulation of $\mathrm{p}-\mathrm{PKC}$ delta protein levels by aldosterone, per se, may be involved in GPR30 activation.

\section{Acknowledgement}

This research was supported by Grant no. RA 57/007 from the Ratchadapiseksompoth Research Fund, Faculty of Medicine, Chulalongkorn University.

\section{References}

Batenburg WW, Jansen PM, van den Bogaerdt AJ, Danser AH. Angiotensin II-aldosterone interaction in human coronary microarteries involves GPR30, EGFR, and endothelial NO synthase. Cardiovasc Res 94,136-143, 2012.

Brailoiu GC, Benamar K, Arterburn JB, Gao E, Rabinowitz JE, Koch WJ, Brailoiu E. Aldosterone increases cardiac vagal tone via $G$ protein-coupled oestrogen receptor activation. J Physiol 59, 4223-4235, 2013.

Buhagiar KA, Hansen PS, Bewick NL, Rasmussen HH. Protein kinase Ce contributes to regulation of the sarcolemmal Na,K-pump. Am J Physiol 50, C1059-C1063, 2001.

Carmeci C, Thompson DA, Ring HZ, Francke U, Weigel RJ. Identification of a gene (GPR30) with homology to the G-protein-coupled receptor superfamily associated with estrogen receptor expression in breast cancer. Genomics 45, 607-617, 1997.

Cheng SB, Graeber CT, Quinn JA, Filardo EJ. Retrograde transport of the transmembrane estrogen receptor, Gprotein-coupled-receptor-30 (GPR30/GPER) from the plasma membrane towards the nucleus. Steroids 76, 892-896, 2011.

Cheng SB, Dong J, Pang Y, LaRocca J, Hixon M, Thomas P, Filardo EJ. Anatomical location and redistribution of G protein-coupled estrogen receptor-1 during the estrus cycle in mouse kidney and specific binding to estrogens but not aldosterone. Mol Cell Endocrinol 382, 950-959, 2014.Dong W, Chen JC, He YL, Xu JJ, Mei YA. Resveratrol inhibits Kv2.2 currents through the estrogen receptor GPR30-mediated PKC pathway. Am J Physiol 305, C547-C557. 2013.

Dooley R, Harvey BJ, Thomas W. Non-genomic actions of aldosterone: From receptors and signals to membrane targets. Mol Cell Endocrinol 350, 223-234, 2012.

Duquesnes N, Lezoualc'h F, Crozatier B. PKC-delta and PKC-epsilon: foes of the same family or strangers? J Mol Cell Cardiol 51, 665-673, 2011. 
Eiam-Ong S, Sinphitukkul K, Manotham K, Eiam-Ong S. Rapid nongenomic action of aldosterone on protein expressions of Hsp90(a and b) and pc-Src in rat kidney. Biomed Res Int 2013, 346480, 2013.

Eiam-Ong S, Sinphitukkul K, Manotham K, Eiam-Ong S. Rapid action of aldosterone on protein expressions of protein kinase $\mathrm{C}$ alpha and alphal sodium potassium adenosine triphosphatase in rat kidney. J Steroids Horm Sci 5, 125, 2014.

Eiam-Ong S, Chaipipat M, Manotham K, Eiam-Ong S. Rapid action of aldosterone on protein levels of sodiumhydrogen exchangers and protein kinase C beta isoforms in rat kidney. Int J Endocrinol 2017, 2975853, 2017.

Fan QW, Cheng C, Knight ZA, Haas-Kogan D, Stokoe D, James CD, McCormick F, Shokat KM, Weiss WA. EGFR signals to mTOR through PKC and independently of Akt in glioma. Sci Signal 2, ra4, 2009.

Feldman RD, Gros R. Unraveling the mechanisms underlying the rapid vascular effects of steroids: sorting out the receptors and the pathways. Br J Pharmacol 163, 1163-1169, 2011.

Fernandez-Llama P, Jimenez W, Bosch-Marcé M, Arroyo V, Nielsen S, Knepper MA. Dysregulation of renal aquaporins and $\mathrm{Na}$ - $\mathrm{Cl}$ cotransporter in $\mathrm{CCl}_{4}$-induced cirrhosis. Kidney Int 58, 216-228, 2000.

Filardo EJ, Graeber CT, Quinn JA, Resnick MB, Giri D, DeLellis RA, Steinhoff MM, Sabo E. Distribution of GPR30, a seven membrane-spanning estrogen receptor, in primary breast cancer and its association with clinicopathologic determinants of tumor progression. Clin Cancer Res 12, 6359-6366, 2006.

Fujigaki Y, Sakakima M, Sun Y, Goto T, Ohashi N, Fukasawa H, Tsuji T, Yamamoto T, Hishida A. Immunohistochemical study on caveolin-1alpha in regenerating process of tubular cells in gentamicin-induced acute tubular injury in rats. Virchows Arch 450, 671-681, 2007.

Funder JW. GPR30, mineralocorticoid receptors, and the rapid vascular effects of aldosterone. Hypertension 57, 370-372, 2011.

Gros R, Ding Q, Sklar LA, Prossnitz EE, Arterburn JB, Chorazyczewski J, Feldman RD. GPR30 expression is required for the mineralocorticoid receptor-independent rapid vascular effects of aldosterone. Hypertension 57, 442-451, 2011a.

Gros R., Ding Q, Davis M, Shaikh R, Liu B, Chorazyczewski J, Pickering JG, Feldman RD. Delineating the receptor mechanisms underlying the rapid vascular contractile effects of aldosterone and estradiol. Can J Physiol Pharmacol 89, 655-663, 2011b.

Gros R, Ding Q, Liu B, Chorazyczewski J, Feldman RD. Aldosterone mediates its rapid effects in vascular endothelial cells through GPER activation. Am J Physiol 304, C532-C540, 2013.

Grossmann C, Gekle M. New aspects of rapid aldosterone signaling. Mol Cell Endocrinol 308, 53-62, 2009.

Harvey BJ, Higgins M. Nongenomic effects of aldosterone on $\mathrm{Ca}^{2+}$ in $\mathrm{M}-1$ cortical collecting duct cells. Kidney Int 57, 1395-1403, 2000.

Kang N, Alexander G, Park JK, Maasch C, Buchwalow I, Luft FC, Haller H. Differential expression of protein kinase C isoforms in streptozotocin-induced diabetic rats. Kidney Int 56, 1737-1750, 1999.

Le Moellic C, Ouvrard-Pascaud A, Capurro C, Cluzeaud F, Fay M, Jaisser F, Farman N, Blot-Chabaud M. Early nongenomic events in aldosterone action in renal collecting duct cells: PKCa activation, mineralocorticoid receptor phosphorylation, and cross-talk with the genomic response. J Am Soc Nephrol 15, 1145-1160, 2004.

Lee YJ, Lee DH, Cho CK, Bae S, Jhon GJ, Lee SJ, Soh JW, Lee YS. HSP25 Inhibits Protein Kinase C delta -mediated Cell Death through Direct Interaction. J Biol Chem 280, 18108-18119, 2005.

Liedtke CM, Cole TS. Antisense oligodeoxynucleotide to PKC delta blocks alphal-adrenergic activation of $\mathrm{Na}-\mathrm{K}-2 \mathrm{Cl}$ cotransport. Am J Physiol 273, C1632-C1640, 1997.

Liedtke CM, Cody D, Cole TS. Differential regulation of Cl transport proteins by PKC in Calu-3 cells. Am J Physiol 280, L739-L747, 2001.

Liedtke CM, Papay R, Cole TS. Modulation of Na-K-2Cl cotransport by intracellular $\mathrm{Cl}^{-}$and protein kinase C-delta in Calu-3 cells. Am J Physiol 282, L1151-L1159, 2002.

Liedtke CM, Cole TS. Activation of NKCC1 by hyperosmotic stress in human tracheal epithelial cells involves PKCdelta and ERK. Biochim Biophys Acta 1589, 77-88, 2002.

Lindsey SH, Yamaleyeva LM, Brosnihan KB, Gallagher PE, Chappell MC. Estrogen receptor GPR30 reduces oxidative stress and proteinuria in the salt-sensitive female mRen2.Lewis rat. Hypertension 58, 665-671, 2011.

Mihailidou A, Mardini M, Funder J. Rapid, nongenomic effects of aldosterone in the heart mediated by protein kinase C epsilon. Endocrinology 145, 773-780, 2004.

Newton AC. Protein kinase C: structure, function, and regulation. J Biol Chem 270, 28495-28498, 1995.

Nishizuka Y. The heterogeneity of protein kinase C and its implications for cellular regulation. Nature 334, 661-665, 1988. 
Nishizuka Y. Intracellular signaling by hydrolysis of phospholipids and activation of protein kinase C. Science 258, 607-614, 1992.

Parker L, Stepto NK, Shaw CS, Serpiello FR, Anderson M, Hare DL, Levinger I. Acute high-intensity interval exercise-induced redox signaling is associated with enhanced insulin sensitivity in obese middle-aged men. Front Physiol 7, 411, 2016.

Queisser N, Schupp N, Stopper H, Schinzel R, Oteiza PI. Aldosterone increases kidney tubule cell oxidants through calcium-mediated activation of NADPH oxidase and nitric oxide synthase. Free Radic Biol Med 51, 19962006, 2011.

Redling S, Pfaff IL, Leitges M, Vallon V. Immunolocalization of protein kinase C isoenzymes $\alpha, \beta$, $\beta$ II, $d$, and $\varepsilon$ in mouse kidney. Am J Physiol 287, F289-F298, 2004.

Ren YL, D’Ambrosio MA, Garvin JL, Leung P, Kutskill K, Wang H, Peterson EL, Carretero OA. Aldosterone sensitizes connecting tubule glomerular feedback via the aldosterone receptor GPR30. Am J Physiol 307, F427F434, 2014.

Ren Y, Janic B, Kutskill K, Peterson EL, Carretero OA. Mechanisms of connecting tubule glomerular feedback enhancement by aldosterone. Am J Physiol 311, F1182-F1188, 2016.

Ridge KM, Dada L, Lecuona E, Bertorello AM, Katz AI, Mochly-Rosen D, Sznajder JI. Dopamine-induced exocytosis of Na,K-ATPase is dependent on activation of protein kinase $\mathrm{C}$ epsilon and delta. Mol Biol Cell 13, $1381-1389,2002$

Schnaper HW. Signal transduction through protein kinase C. Pediatr Nephrol 14, 254-258, 2000.

Sinphitukkul K, Eiam-Ong S, Manotham K, Eiam-Ong S. Nongenomic effects of aldosterone on renal protein expressions of pEGFR and pERK1/2 in rat kidney. Am J Nephrol 33, 111-120, 2011.

Thomas W, McEneaney V, Harvey BJ. Aldosterone-stimulated PKC signaling cascades: From receptor to effector. Biochem Soc Trans 35, 1049-1051, 2007.

Thomas W, Harvey BJ. Mechanisms underlying rapid aldosterone effects in the kidney. Annu Rev Physiol 73, 335337, 2011.

Zhu X, Manning RD Jr, Lu D, Gomez-Sanchez CE, Fu Y, Juncos LA, Liu R. Aldosterone stimulates superoxide production in macula densa cells. Am J Physiol 301, F529-F535, 2011. 